\title{
A New Generation Lean Gasoline Engine for Premium Vehicle $\mathrm{CO}_{2}$ Reduction
}

\author{
Author, co-author (Do NOT enter this information. It will be pulled from participant tab in \\ MyTechZone) \\ Affiliation (Do NOT enter this information. It will be pulled from participant tab in MyTechZone)
}

\begin{abstract}
In an era of rapidly increasing vehicle electrification, the gasoline engine remains a vital part of the passenger car powertrain portfolio. Lean-burn combustion is a formidable means for reducing the $\mathrm{CO}_{2}$ emissions of gasoline engines but demands the use of sophisticated emissions control.
\end{abstract}

A 2.0 litre turbocharged direct-injection gasoline engine has been developed with a lean homogeneous combustion system matched to a robust lean and stoichiometric-capable exhaust aftertreatment. The aftertreatment system includes an SCR system and a GPF with filtration down to $10 \mathrm{~nm}$ particle size. The engine is equipped with a continuously variable valve-lift system, high-tumble ports and a highenergy ignition system; the boosting system comprises a variable geometry turbocharger and a $48 \mathrm{~V}$ electrical supercharger.

The work reported formed part of the PaREGEn (Particle Reduced, Efficient Gasoline Engines) project under the Horizon 2020 framework programme. In this project, further development of gasoline engines as used in mid to premium-sized cars was undertaken, with the objective to reduce $\mathrm{CO}_{2}$ emissions by $15 \%$ under Euro $6 \mathrm{~d}$ RDE (Real Driving Emissions) legislation and with particle number emissions measured down to $10 \mathrm{~nm}$.

This paper will give a detailed treatment of the multi-cylinder engine and vehicle development undertaken. The engine delivered BSFC benefits exceeding $10 \%$ and a peak brake thermal efficiency of $42 \%$, while the vehicle demonstrated a $\mathrm{NO}_{\mathrm{x}}$ conformity factor below $1.0 \mathrm{in}$ independent RDE tests.

\section{Introduction}

Growing road traffic in Europe has resulted in detrimental effects on the environment and on public health, despite increasingly stringent emission standards. Carbon dioxide $\left(\mathrm{CO}_{2}\right)$ and noxious emissions may not be sufficiently reduced in real driving, whilst some engine technologies may have led to increases in the emissions of nanoparticles that are not detected by current certification procedures. In the European Green Vehicles Initiative call GV-02-2016, within the Horizon 2020 framework programme, the objective was to develop a new generation of engine technologies that are significantly more fuel efficient than the best 2015 equivalent vehicles under real driving conditions, and to demonstrate pollutant emissions levels compliant with the Euro $6 \mathrm{RDE}$ limits and particle number emissions measured down to a $10 \mathrm{~nm}$ size threshold [1].
In the PaREGEn (Particle Reduced, Efficient Gasoline Engines) project $[2,3]$, a consortium including OEMs, research institutions, Tier 1 suppliers and engineering service providers, has focussed on gasoline engines as used in mid-sized and premium-sized passenger cars. An overview of the complete project is shown in Figure 1. With the electrification of smaller vehicle's powertrains (suitable for zero tailpipe emissions in urban environments), addressing larger cars was especially important. The requirement for clean, efficient and economic engines for cars regularly used for inter-urban and regional transport was urgent, and the solutions addressed the societal challenges of air quality, decarbonisation and cost-effective mobility.

Lean-burn operation has been known to improve fuel economy since the earliest internal-combustion engines were developed [4]. Enleanment can reduce both heat losses and pumping work and increase the ratio of specific heats of the working fluids. The first direct-injection (DI) gasoline engines to enter mass production utilised lean-stratified operation [5-8], their wall-guided combustion systems were superseded by spray-guided engines with piezo-electric injectors [9-12]. Boosted lean direct-injection gasoline engines were first demonstrated almost 20 years ago $[13,14]$, they entered series production in 2012 [15].

In order to meet the combined climate and air quality challenges described above with lean gasoline engines, a new generation of technology solutions is required. The focus has returned to leanhomogeneous combustion systems, which produce the lowest engineout $\mathrm{NO}_{\mathrm{x}}$ emissions. Advanced fuel-injection, ignition, valvetrain and boosting technologies have been employed to increase the air-fuel ratio possible with stable combustion [16-22]. This paper presents an experimental study of both multi-cylinder engine and vehicle performance with a lean-homogeneous combustion system. The engine and aftertreatment system have delivered improved brake thermal efficiency and $\mathrm{CO}_{2}$ emissions, while also controlling drivecycle and real-world $\mathrm{NO}_{\mathrm{x}}$ emissions.

\section{Engine and Vehicle Concept}

The work reported sought to advance the state-of-the-art for lean-burn engine technology by combining developments in fuel-injection, boosting and continuously variable valve-lift (CVVL) technologies in a high compression-ratio Miller Cycle engine. As mentioned above, fine sub-23 nm particles are also a special focus; work has concentrated on maintaining low levels during real-world transient driving conditions. Key elements of the project and engine have been introduced in an earlier paper by the authors [23] 


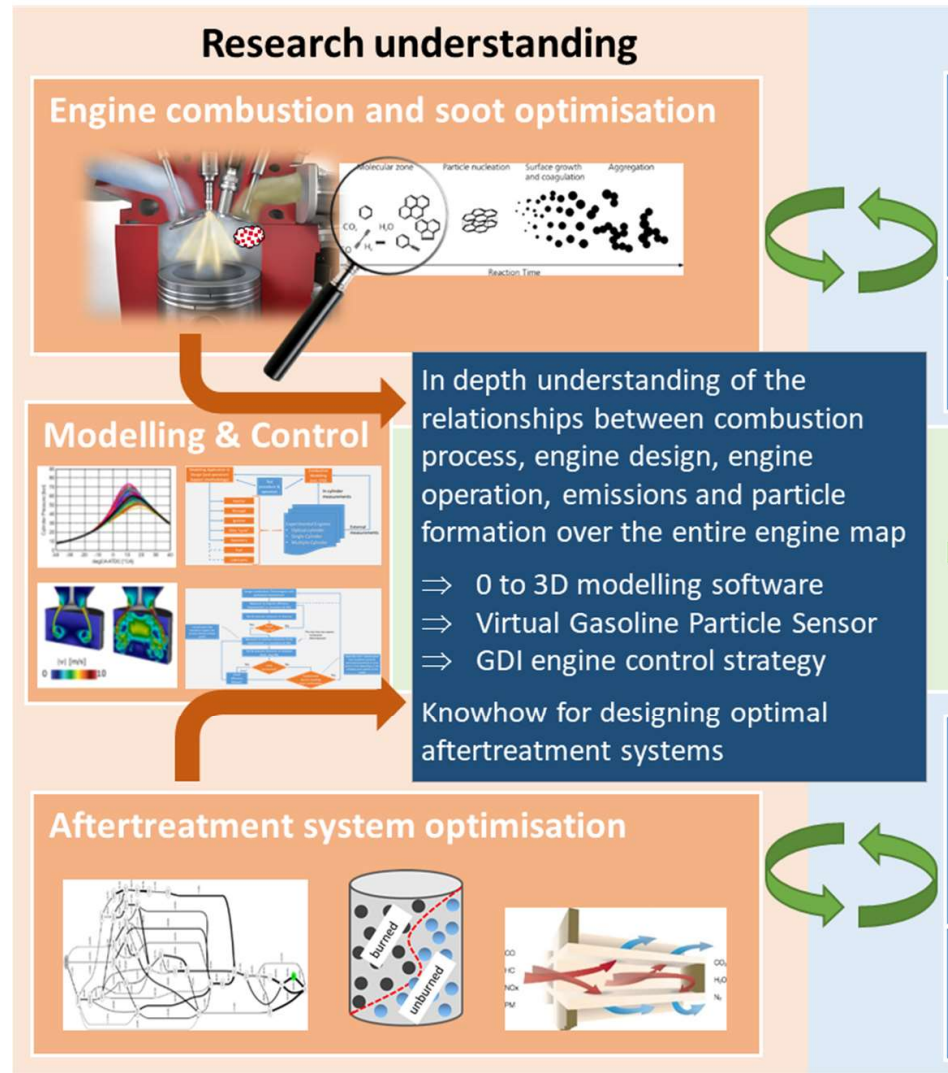

Figure 1 Overview of the PaREGEn project

The base engine for this study was Jaguar Land Rover's Ingenium fourcylinder gasoline engine at a $200 \mathrm{PS}(147 \mathrm{~kW})$ performance level [24]. The project engine contains a revised combustion system combined with a range of technology to meet future legislative emissions and $\mathrm{CO}_{2}$ requirements, whilst delivering competitive engine performance and premium refinement. The project engine specification is presented in Table 1.

Table 1 Engine specification
\begin{tabular}{|l|l|l|}
\hline Bore & {$[\mathrm{mm}]$} & 83 \\
\hline Stroke & {$[\mathrm{mm}]$} & 92 \\
\hline Number of cylinders & {$[-]$} & 4 \\
\hline Engine displacement & {$[\mathrm{cm} 3]$} & 1997 \\
\hline $\begin{array}{l}\text { Compression ratio } \\
\text { (nominal) }\end{array}$ & {$[-]$} & $\begin{array}{l}11.0: 1 \text { (interim) } \\
12.5: 1 \text { (final) }\end{array}$ \\
\hline Rated power & $\mathrm{kW}$ & 147 (at $5500 \mathrm{rev} / \mathrm{min})$ \\
\hline Peak torque & $\mathrm{Nm}$ & 320 (at $1200-4500$ rev/min) \\
\hline Valvetrain & {$[-]$} & DOHC, dual VCT, intake CVVL \\
\hline Boosting system & {$[-]$} & $\begin{array}{l}\text { VNT turbo, } 48 \mathrm{~V} \text { electric } \\
\text { supercharger }\end{array}$ \\
\hline
\end{tabular}

Page 2 of 12

$12 / 01 / 2021$

\section{Innovation \& Demonstration}

Development of Miller Cycle stoichiometric Combustion Engine

- Improved bore:stroke ratio (and downsizing)

- $\mathrm{H}_{2} \mathrm{O}$ injection and improved fuel injection

- SVL on intake \& exhaust

- Variable charge mode and new turbocharger

- Implementation 0 to 3D modelling software, VGPS, advances

in GDI control strategy

- Implementation of aftertreatment (TWC-GPF)

\section{Impact Assessment}

Target setting, tracking and assessment

Independent testing of EU6RDE and $\mathrm{CO}_{2}$ improvement

Development of lean Miller Cycle combustion engine

- High compression Miller Cycle engine

- Lean combustion with 'dry' air dilution

- Continuously-variable valve-lift

- Low-pressure EGR

- Implementation 0 to 3D modelling software, vGPS, advances

in control strategy

- Implementation of aftertreatment (lean $\mathrm{NO}_{\mathrm{x}}$ reduction \& GPF)
The geometric compression ratio of the engine as-designed was 12.5:1 (shown in Table 1 as 'final'), but the correct pistons were not available until later in the project, so some engine testing and the vehicle development work were undertaken with lower compression ratio pistons. For this reason, 11.0:1 is shown as the 'interim' compression ratio.

The combustion system is implemented with a multi-mode approach, as shown in Figure 2. Lean-homogeneous operation is used at lower speeds and loads, with stoichiometric operation elsewhere to balance high performance with the most straightforward emissions control. The size of the lean window depends both on the combustion system and on emissions considerations. If lean operation can be maximised while meeting the required RDE conformity factors, the $\mathrm{CO}_{2}$ benefit is also maximised.

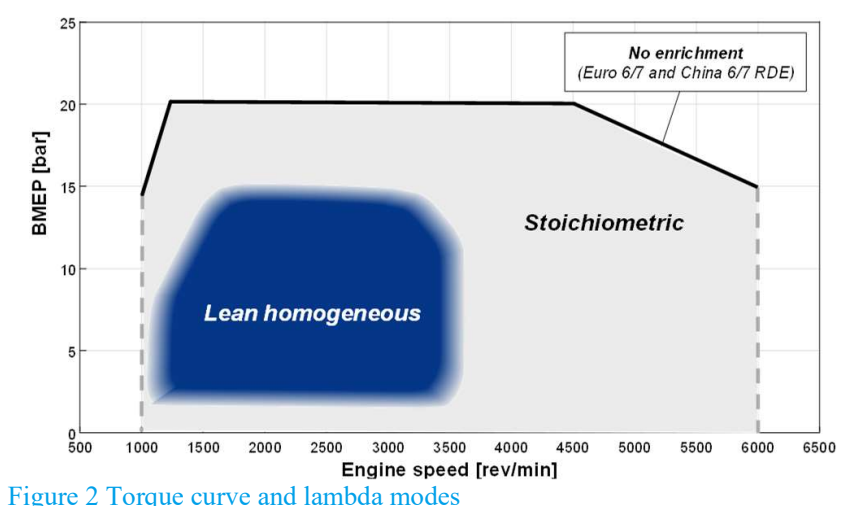

Figure 2 Torque curve and lambda modes 


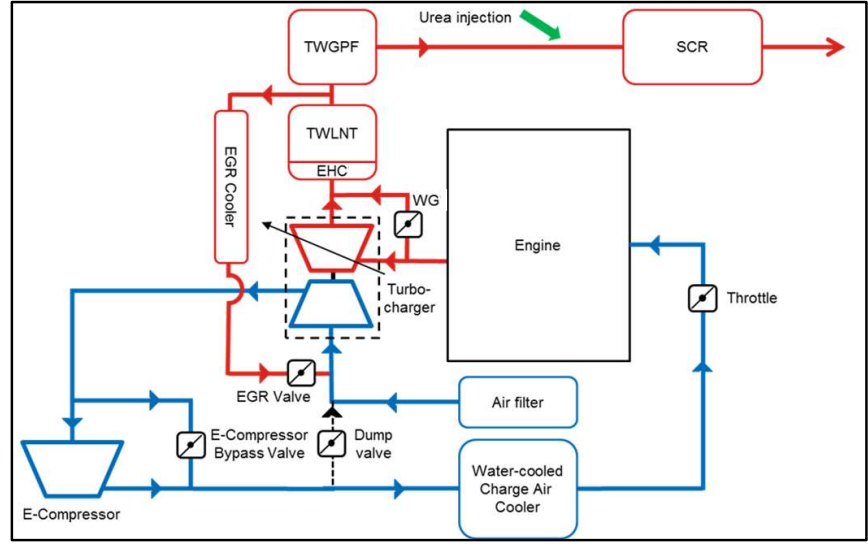

Figure 3 Engine intake and exhaust schematic

A schematic of the intake and exhaust layout is shown in Figure 3. The main components of these systems will be described in the following sections.

\section{Combustion System}

To support high thermal efficiency and provide the combustion stability necessary to operate at very lean mixtures, the combustion system was designed for an increased geometric compression ratio and increased levels of charge motion. The increased charge motion was achieved while ensuring the high air-mass flow necessary for lean operation could be delivered with low pumping losses. A representation of the ports and combustion chamber is shown in Figure 4. The intake ports were updated so that air flow over the top of the intake valves was promoted and flow below the valves (close to the cylinder wall) was reduced. This led to turbulence intensity being increased by $17 \%$ at the rated power condition, according to 3-D CFD calculations.

The CVVL system was used in conjunction with dual VCT, providing maximum flexibility of intake valve lift profiles to achieve the optimum balance of pumping losses, effective compression ratio, charge motion and internal residuals. The high level of flexibility also allows independent optimisation for stoichiometric and lean operation [21].

In common with the Ingenium family, the PaREGEn engine retained a centrally-mounted 6-hole fuel injector. However, the specification of the injector, fuel system and ignition system were all modified or upgraded for this engine. In conjunction with Bosch, the injection spray pattern has been optimised for this engine, and the FIE uprated to operate at pressures of up to 350 bar. The injector spray pattern was designed to maximise mixture homogeneity while not increasing wall or valve wetting.

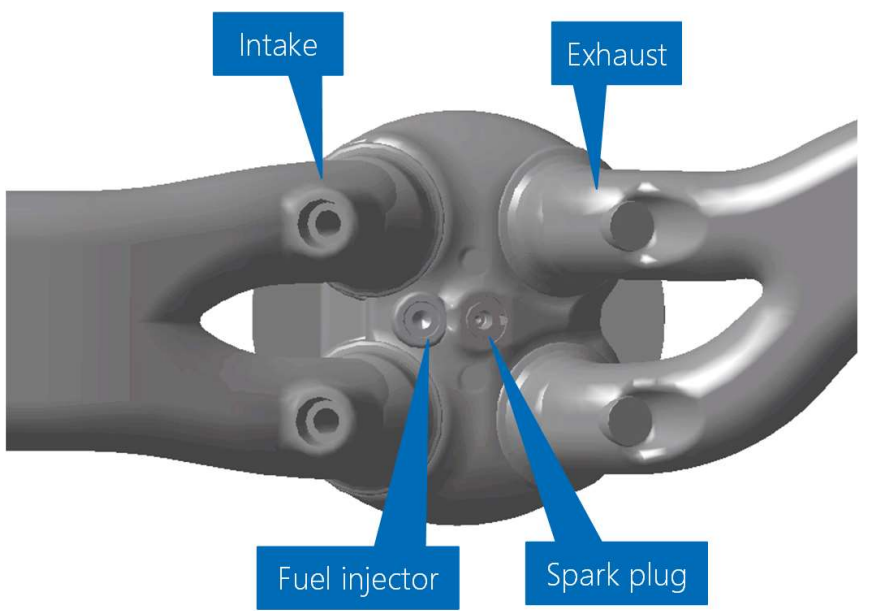

Figure 4 Combustion system geometry

To improve combustion stability and enable operation at leaner conditions, an advanced high-energy ignition system was supplied by Bosch [25]. This system is capable of running with up to $500 \mathrm{~mJ}$ ignition energy and can operate in a number of different ignition modes, including single-strike, multiple-strike, and continuous ignition modes. The system can promote early flame kernel development and reduce the likelihood of spark blow-out at high spark stretch rates, such as under high gas flow conditions with the increased levels of charge motion. Initial studies on a single-cylinder research engine found the continuous ignition mode had particular promise, increasing the EGR tolerance of the engine by up to $5 \%$ and reducing the burn duration by several degrees, relative to the other modes tested.

A cooled Low-Pressure Exhaust Gas Recirculation (LPEGR) system has also been employed to manage exhaust temperature at rated power conditions and minimise (or completely eliminate) fuel enrichment in this region.

\section{Boosting System}

A Garrett Variable Nozzle Turbine (VNT) was chosen as the main boosting device (Figure 5), supplemented by a $48 \mathrm{~V}$ electric compressor also manufactured by Garrett. This boosting system was found to offer the best compromise between low turbine inlet pressures and transient response [26], the low turbine inlet pressures thereby reducing pumping losses and trapped residuals and, in turn, reducing boost pressure requirement, an important consideration for a lean boosted engine. 


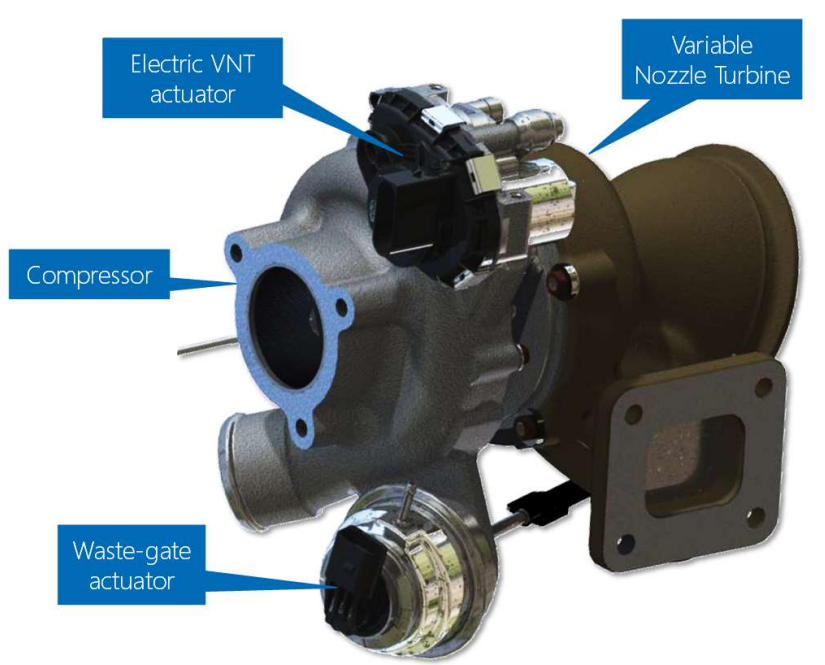

Figure 5 Variable Nozzle Turbine turbocharger

A $48 \mathrm{~V}$ electric compressor (Figure 6) is used in conjunction with and downstream of the VNT compressor, to provide increased boost pressure capability when the turbocharger is surge- or turbine-power limited. In addition, the electric compressor is also used during stoichiometric-to-lean mode switching, where it helps to deliver the additional air required to achieve lean homogeneous combustion whilst maintaining engine torque.

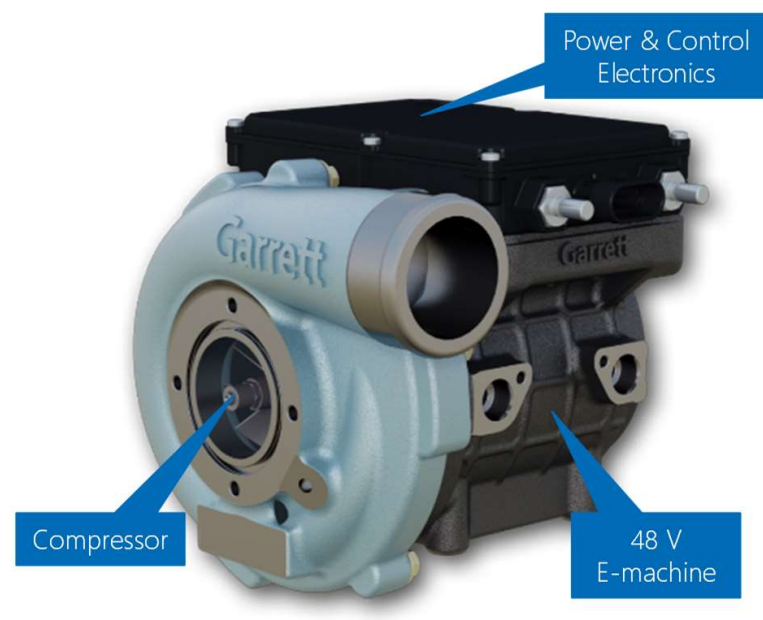

Figure $648 \mathrm{~V}$ electric compressor

\section{Emissions Control}

The aftertreatment is designed to operate under both lean and stoichiometric conditions. Lean $\mathrm{NO}_{\mathrm{x}}$ reduction is facilitated by a Lean $\mathrm{NO}_{\mathrm{x}}$ Trap (LNT) in combination with a downstream active Selective Catalytic Reduction (SCR) system. A Gasoline Particulate Filter (GPF) has been selected to allow particle reduction down to $10 \mathrm{~nm}$ without significantly increasing the overall system back-pressure. Both LNT and GPF have been coated to facilitate three-way $\left(\mathrm{NO}_{x}, \mathrm{CO}\right.$ and $\mathrm{HC}$ ) catalytic converter capability under stoichiometric conditions, they are herein referred to as TWLNT and TWGPF respectively. All three catalysts have been supplied by Johnson Matthey.

\section{System Layout}

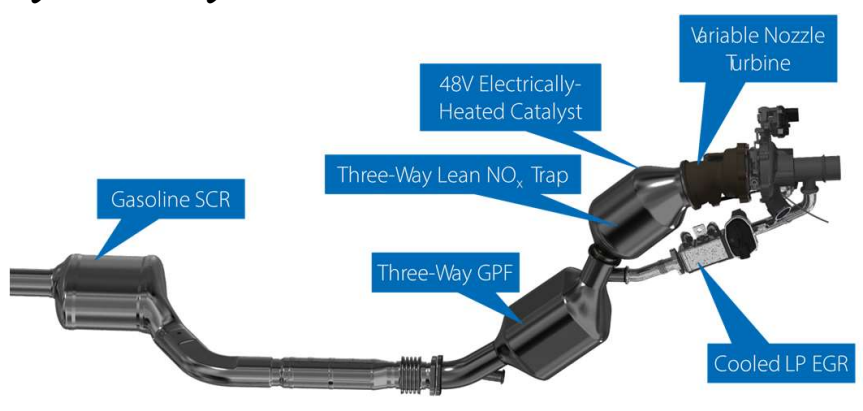

Figure 7 Layout of the aftertreatment system

The aftertreatment layout is shown in Figure 7. In order to optimise the catalyst response time from cold-start conditions and during the transitions between lean and stoichiometric operation, the TWLNT was coated onto an electrically-heated catalyst (EHC). Specific requirements of the $\mathrm{EHC}$ were for it to run from a $48 \mathrm{~V}$ supply, to deliver a heating power output of up to $3 \mathrm{~kW}$. The TWGPF is located closely behind the TWLNT to maximise exhaust gas temperatures at TWGPF inlet, assisting both gaseous emissions performance and the regeneration of accumulated soot through combustion. The SCR catalyst is located in an underfloor position, downstream of the urea dosing module; gas temperatures at the inlet to the SCR are typically expected to be $\sim 140{ }^{\circ} \mathrm{C}$ cooler than those at the exhaust manifold. Compared with copper-based technologies, an iron-based SCR (FeSCR) technology was chosen based on its higher durability under environments with little or no oxygen present (as will be the case under stoichiometric operation) and low selectivity towards forming nitrous oxide $\left(\mathrm{N}_{2} \mathrm{O}\right)$.

\section{Gasoline Particle Filter Development}

A key requirement for the PaREGEn project was to deliver compliance with the particle number legislation for Euro $6 \mathrm{~d}$ down to a particle size of $10 \mathrm{~nm}$ (below the $23 \mathrm{~nm}$ threshold currently defined). Evaluation of the filtration performance of different TWGPF catalyst formulations was carried out using a 2017 model year Jaguar XE 2.0 litre GTDi on a chassis dynamometer. Particulate numbers at the tailpipe were measured using a Horiba MEXA-2000 SPCS analyser to give an accurate reading down to $23 \mathrm{~nm}$, as well as a Cambustion DMS500 to provide representative data on particle size distribution down to $10 \mathrm{~nm}$.

Figure 8 compares the filtration efficiency of two development formulations against a Baseline formulation when evaluated over the World-Harmonised Light-Duty Test Cycle (WLTC); filtration efficiencies for different diameter ranges are shown. Dev1 was developed using new materials with the goal of minimising pressure drop across the GPF (backpressure), which is desirable for enabling the engine to deliver peak power and optimised driveability. Dev2 uses a combination of new materials and processing methods with the goal of optimising filtration efficiency whilst still providing some improvements in backpressure relative to the reference. All three formulations show higher filtration efficiencies at 10-23 nm compared with $23 \mathrm{~nm}+$, likely due to the dominance of the diffusion filtration mechanism at smaller particle sizes. However, both development formulations show an improvement in filtration efficiency at 10-23 $\mathrm{nm}$, with Dev2 showing the best overall filtration efficiency at all particle sizes. 


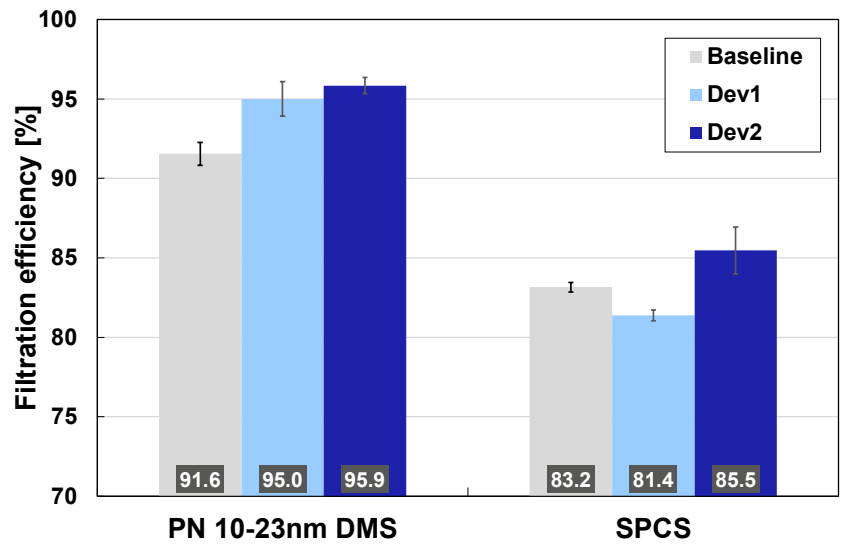

Figure 8 Filtration efficiency summary at different particle size ranges measured over WLTC

Dev2 was also shown to demonstrate favourable back-pressure characteristics (Figure 9) compared with the Baseline formulation,. Hence, Dev2 was chosen as the preferred TWGPF formulation.

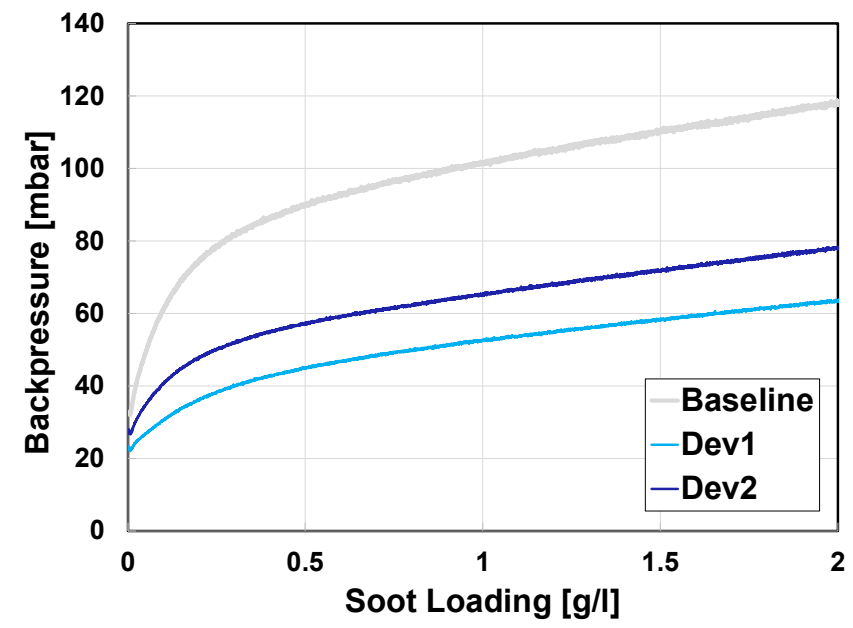

Figure 9 Comparison of soot loaded backpressure

GPF substrates of varying web thicknesses, supplied by NGK, were also considered. Both the Baseline and Dev2 TWGPF formulations were coated on $300 \mathrm{cpsi}$ substrates with web thicknesses of 8 mil and 12 mil, hereafter referred to as $300 / 8$ and $300 / 12$, respectively; there were evaluated over the WLTC, as shown in Figure 10. The Baseline formulation showed increased filtration efficiency when the thicker walled substrate was used. The Dev2 formulation showed less sensitivity of PN filtration efficiency to wall thickness, as seen in the DMS data. In both instances the higher web thickness resulted in a penalty in backpressure. Overall, the Dev2 formulation on a $300 / 8$ substrate remained the best compromise of PN filtration efficiency and backpressure.

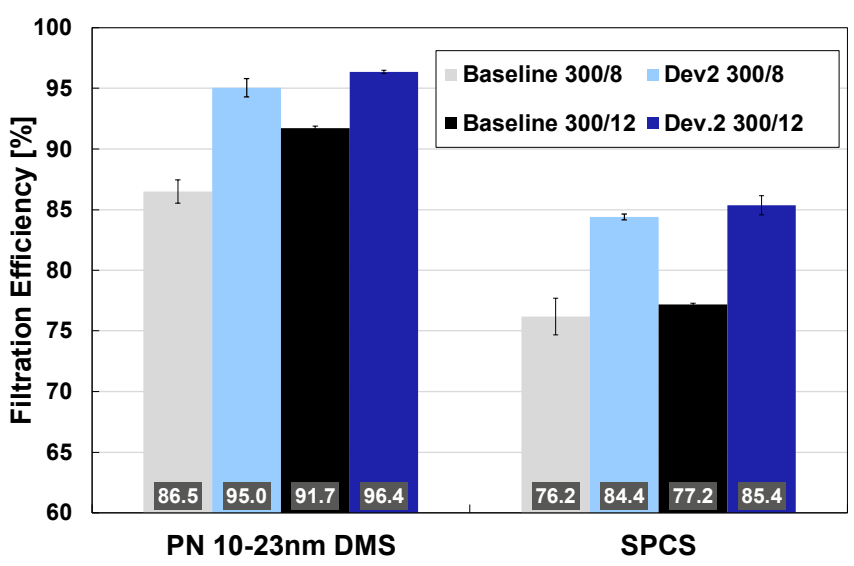

Figure 10 Filtration efficiency summary for different TWGPF and substrate combinations over WLTC

\section{Lean NOx Aftertreatment Development}

The ratio of $\mathrm{NO}_{2}$ : $\mathrm{NO}$ in the exhaust gas can have a significant bearing on the SCR conversion efficiency (SCR reactions were described in detail in [20]). Figure 11 shows the effect of temperature and $\mathrm{NO}_{2}: \mathrm{NO}_{\mathrm{x}}$ ratio on SCR conversion efficiency for an Fe-SCR catalyst, aged hydrothermally for 4 hours at $900{ }^{\circ} \mathrm{C}$ in a gas mix of $2 \% \mathrm{O}_{2}: 10 \%$ $\mathrm{H}_{2} \mathrm{O}: \mathrm{N}_{2}$ balance. The tests were carried out on a synthetic gas rig using a gas mix containing 500 ppm total $\mathrm{NO}_{\mathrm{x}}\left(\mathrm{NO}+\mathrm{NO}_{2}\right)$ and an $\mathrm{NH}_{3}: \mathrm{NO}_{x}$ ratio of $1.5: 1$, at a gas-hourly space velocity (GHSV) of $60,000 \mathrm{hr}^{-1}$. The results show that having a high proportion of $\mathrm{NO}_{2}$ (preferably up to $50 \%$ of total $\mathrm{NO}_{\mathrm{x}}$ ) greatly improves $\mathrm{SCR}$ conversion, especially at low temperatures. For the lean-burn gasoline application, however, $\mathrm{NO}_{2}: \mathrm{NO}_{\mathrm{x}}$ ratios at $\mathrm{SCR}$ inlet are not expected to exceed 10 $\%$, due to the tendency for the upstream TWLNT to consume $\mathrm{NO}_{2}$ before it reaches the SCR.

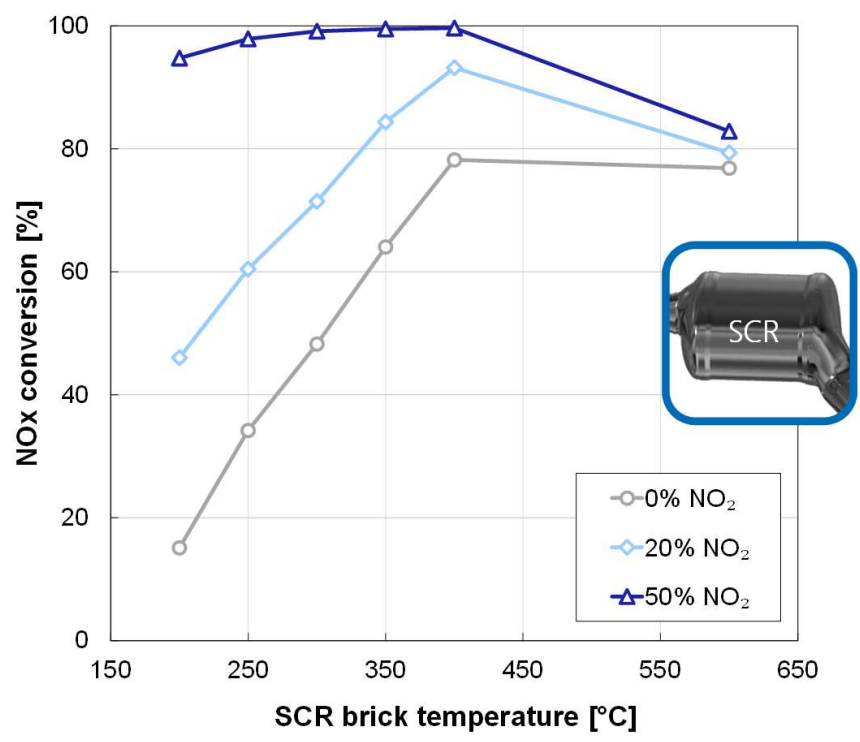

Figure 11 Impact of $\mathrm{NO}: \mathrm{NO}_{2}$ ratio on $\mathrm{SCR}$ performance

As a means of boosting the $\mathrm{NO}_{2}: \mathrm{NO}_{\mathrm{x}}$ at the SCR inlet, trials were carried out using a modification of the Dev2 TWGPF formulation to include an additional component to promote $\mathrm{NO}_{2}$ make, as shown in Figure 12. The benefits of the modified TWGPF design on the 
downstream SCR conversion efficiency when evaluated on the multicylinder engine are shown in Figure 13.

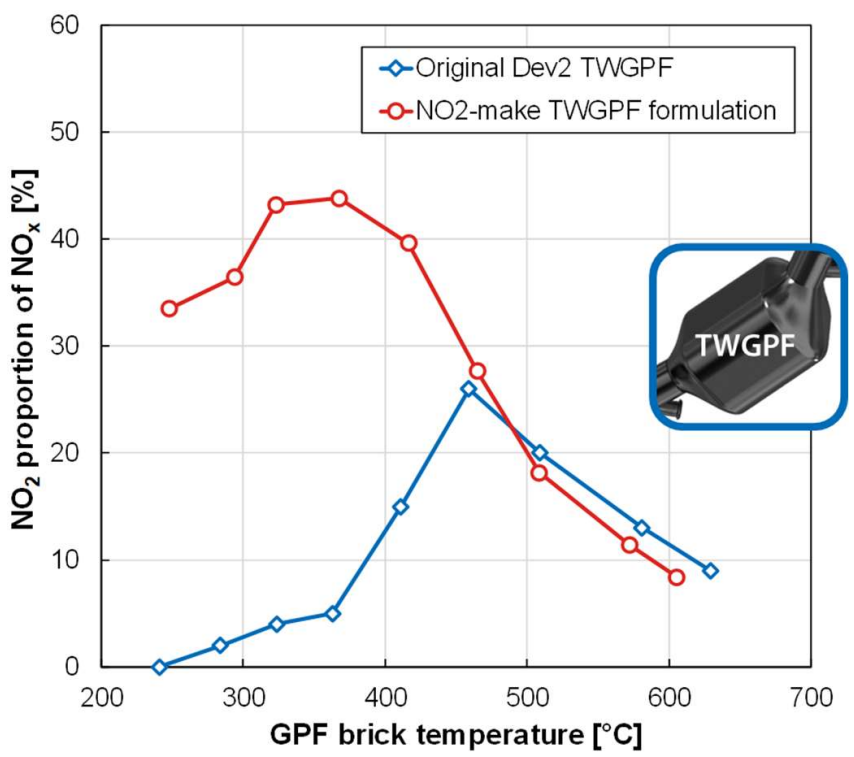

Figure 12 Comparison of original Dev 2 and $\mathrm{NO}_{2}$ make TWGPF

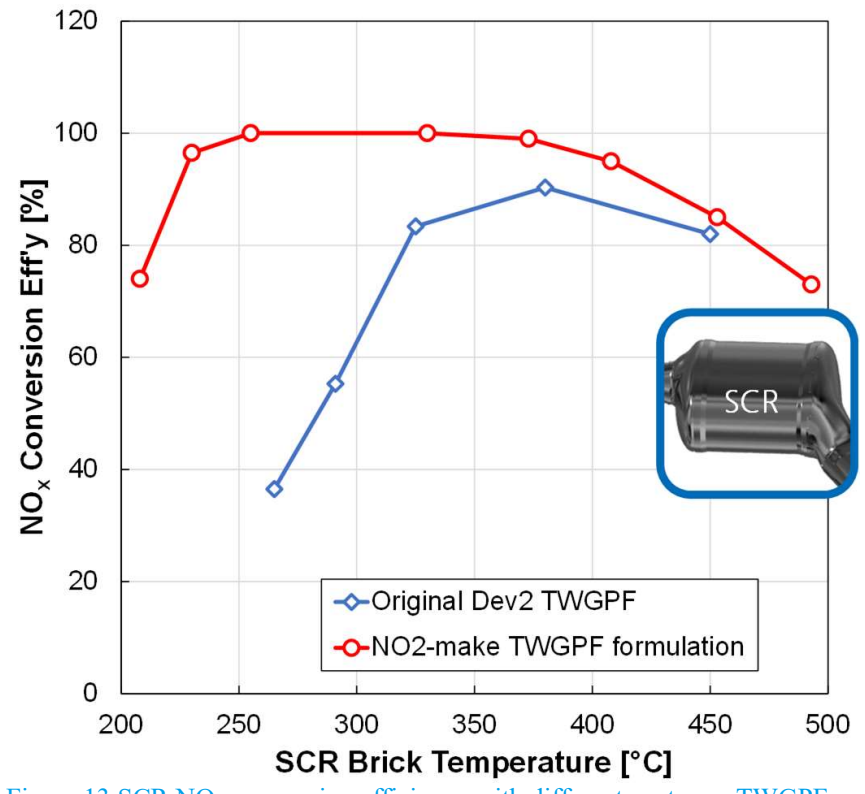

Figure 13 SCR NOx conversion efficiency with different upstream TWGPFs

The revised filter was evaluated on the chassis dynamometer on the same Jaguar XE 2.0 litre GTDi. The second-by-second PN measurements pre- and post-TWGPF, as measured using the Horiba SPCS, for both filters are shown in Figure 14. The new TWGPF design demonstrated high filtration efficiency $(\sim 90 \%)$. Following further revisions of the coating to optimise both filtration and backpressure characteristics, the new TWGPF design was taken forward for demonstration on the engine.

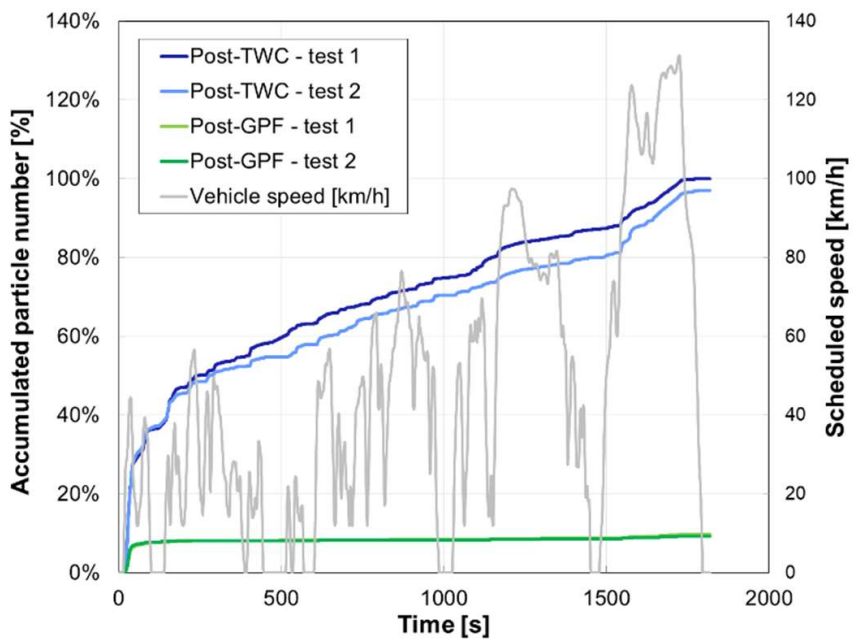

Figure 14 WLTC PN emissions - TWGPF with $\mathrm{NO}_{2}$-make functionality

\section{Control System}

The engine control unit (ECU) platform adopted for the project is the Schaeffler PROtroniC system. This system provides a high degree of flexibility when designing the control approach for the engine, actuators and aftertreatment. Key elements of the control system have been implemented and tested successfully on both engine testbed and vehicle. The ECU is also set up to communicate with the rest of the vehicle network, enabling the car to be driven in a variety of operating conditions.

Combustion control is enhanced with the adoption of cylinder pressure feedback, allowing improved control of combustion phasing and indicated mean effective pressure (IMEP). A $48 \mathrm{~V}$ system architecture is also configured to drive the electric compressor and EHC. Smooth coordination of all these systems is critical to achieving good transient performance, fuel consumption and emissions control.

Under lean conditions, the optimal settings can differ significantly from those used under stoichiometric conditions. To allow for this, the control system has been specified with separate setpoints for all major actuators under lean conditions. Calibration of these setpoints is described further in the Lean Mode Mapping section. The "enable" criteria for lean operation are based on a number of conditions including: engine coolant temperature, engine speed and load, aftertreatment operating temperature and the $48 \mathrm{~V}$ system status. When the threshold values for parameters relating to each of these criteria are met, a switch from stoichiometric to lean is permitted. The control strategy allows for flexibility to define the transition between one mode and the other. The optimal solution involves a rapid change, to minimise time spent within the high-NOx-generating lambda region between lambda 1.05 and 1.30, whilst minimising any torque disturbances associated with the combustion mode change.

\section{Engine Testing}

The multi-cylinder lean-burn engine was installed on a transient dynamometer testbed at the University of Brighton. The test facility included the full vehicle-level exhaust aftertreatment system to accurately reflect the associated backpressure and provide early results for the aftertreatment performance.

The results from the stoichiometric full load power curve (FLPC) testing are presented in Figure 15. In previous testing without the 
electric compressor, the target torque curve was not achieved at engine speeds below $2500 \mathrm{rpm}$. Combinations of valve events which would have led to scavenging were avoided. Testing with the electric compressor resulted in the target torque curve being met at all engine speeds. As the engine speed increases, the VNT was able to generate more boost pressure from the increasing exhaust mass flow and enthalpy, therefore the electric compressor speed required to achieve the target brake torque reduces until, at $2500 \mathrm{rpm}$, the electric compressor is no longer required. The increased mass flow from using the electric compressor at low engine speeds also allows the VNT to run at higher speed and generate more boost. This can be seen in the difference between the red and blue dashed lines in Figure 15.

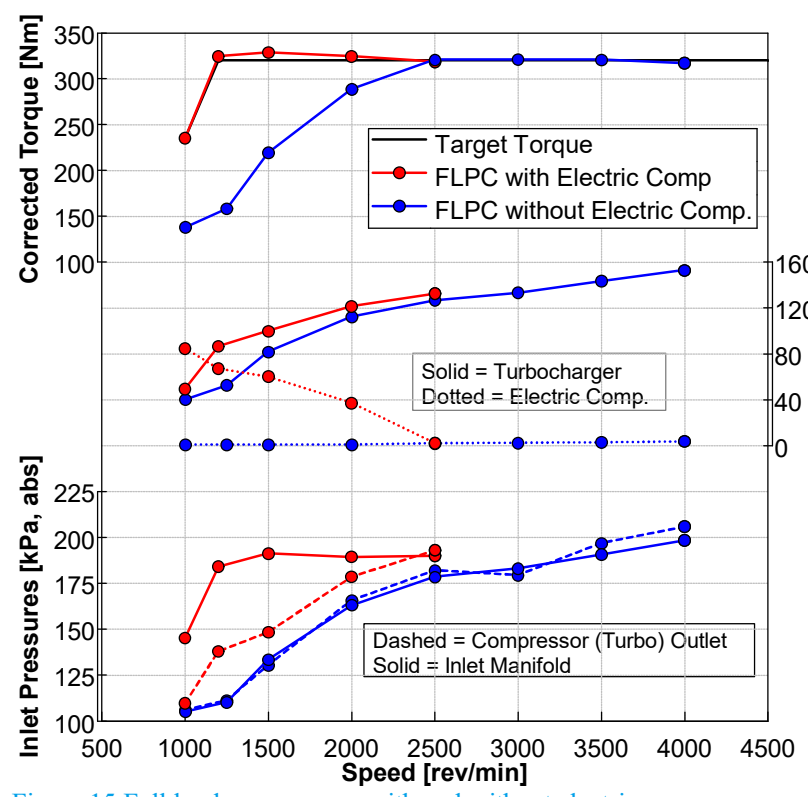

Figure 15 Full load power curve with and without electric compressor

\section{Lean Mode Mapping}

The engine was mapped using a Design of Experiments (DoE) approach with Stochastic Process Methods (SPM) modelling [31]. The experimental design included lambda, combustion phasing, intake and exhaust cam timing and CVVL closing angle as input variables. Exhaust lambda for the lean homogeneous mode is shown in Figure 16 , based on 51 key-points. The air-fuel ratio (or lambda) employed is a balance between the desire to run as lean as possible, in order to minimise NOx emissions and improve fuel economy, and the requirement to maintain acceptable combustion stability and vehicle driveability. CVVL settings were also an important consideration: in many cases the best fuel economy was achieved with more aggressive EIVC settings and a slightly less lean mixture. Under the most favourable conditions, lambda values close to 1.6 were selected, but at low loads the lambda was reduced in order to maintain combustion stability.

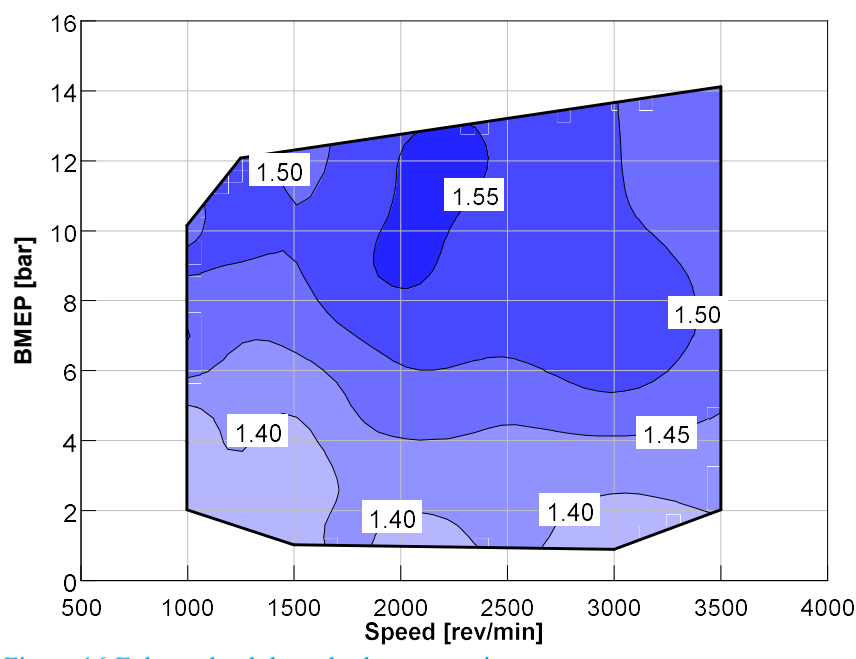

Figure 16 Exhaust lambda under lean operation

Burn durations (10-90\% mass fraction burned (MFB)) for lean operation are shown in Figure 17. This data confirms that the efforts made to provide high air motion succeeded, as the burn durations for lean combustion are comparable to the baseline stoichiometric engine.

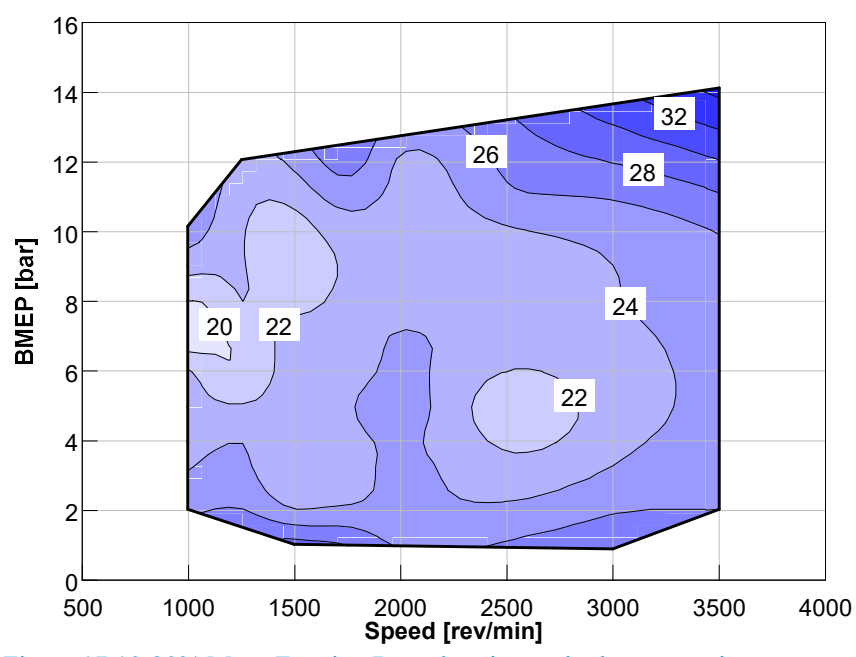

Figure 17 10-90\% Mean Fraction Burn duration under lean operation

Figure 18 shows the volume concentration of engine-out NOx emissions in the lean mode, which is up to $90 \%$ lower than that for the stoichiometric baseline engine. It is critical to reduce the engine-out NOx emissions as much as possible in order to reduce the burden on the lean aftertreatment system. 


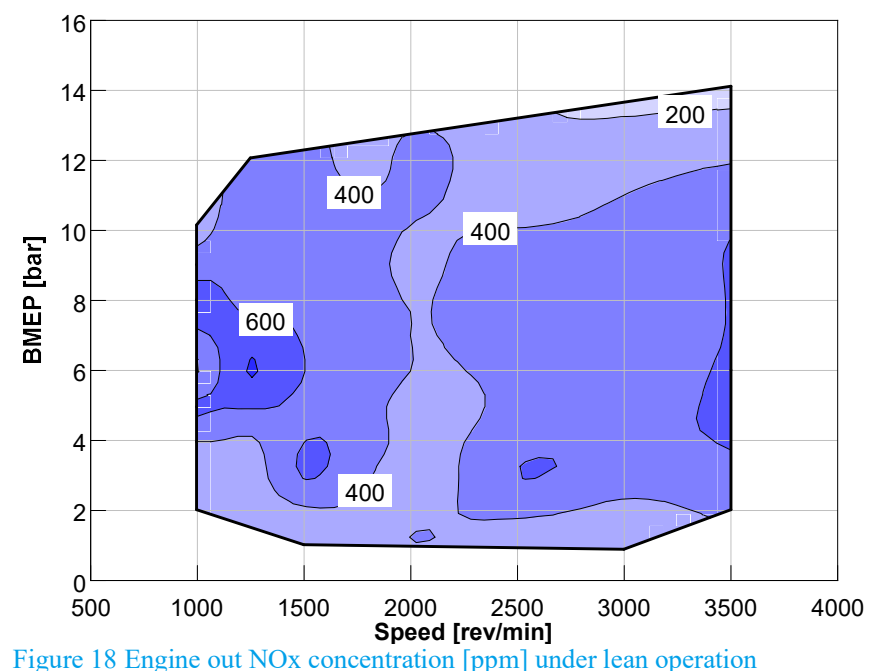

Figure 18 Engine out NOx concentration [ppm] under lean operation

Figure 19 presents the BSFC benefit of the PaREGEn prototype engine over the stoichiometric baseline engine. The BSFC benefit (which includes the impact of increased compression ratio) is greater than $10 \%$ over a wide range of loads, in a high-residency region for the project vehicle. This benefit arises largely from reductions in in-cylinder and exhaust heat losses. The low pumping losses of the CVVL baseline engine are highlighted by the relatively small BSFC benefit at low loads.

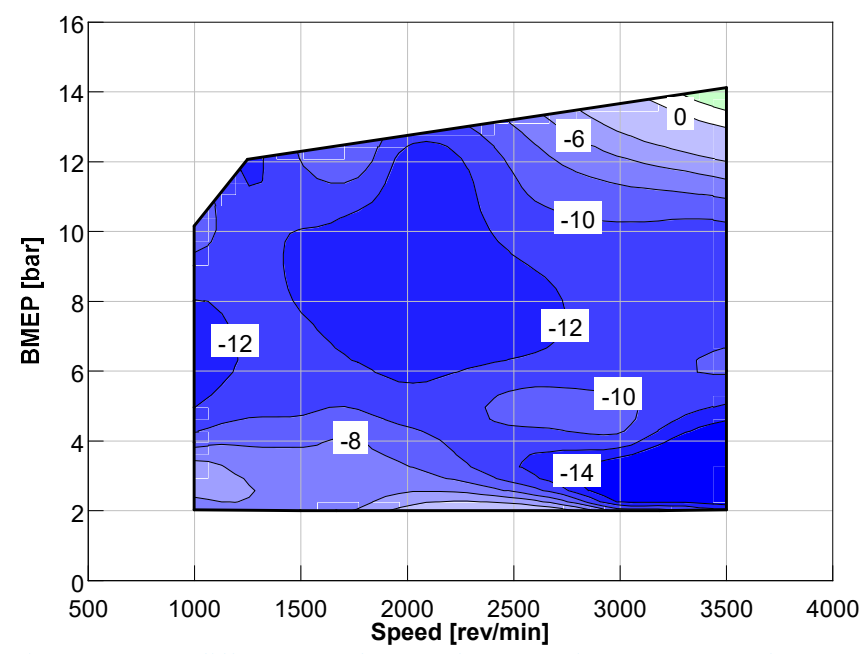

Figure 19 BSFC difference [\%] between lean operation PaREGEn and stoichiometric operation baseline engine

\section{Key-Point Optimisation}

Key-point optimisation was then undertaken to see if the lean air-fuel ratio could be further increased and BSFC improved, while maintaining combustion stability (a limit of $3 \%$ for CoV NIMEP was applied).

Page 8 of 12

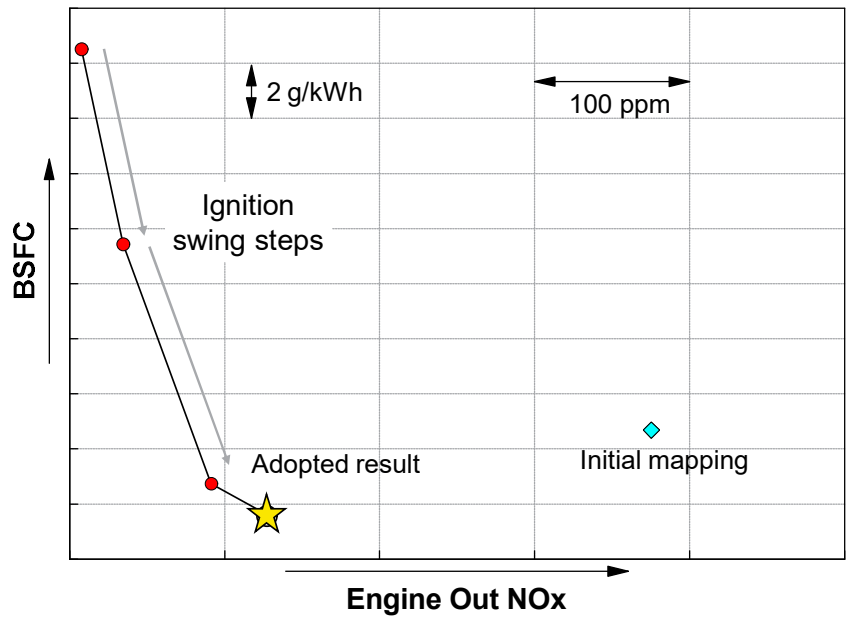

Figure 20 BSFC vs. NOx trade-off with varying ignition timing at 2000 $\mathrm{rev} / \mathrm{min}, 12$ bar BMEP

At each key-point the following sequence of tests was undertaken:

1. Lambda swings were undertaken at a range of cam timing settings

2. The cam timing and lambda settings achieving the best BSFC (within combustion stability limits) were then selected

3. An ignition timing swing was carried out to study the trade-off between BSFC and NOx emissions

4. Finally CVVL closing angle was optimised

In Figure 20 the output from step 3 of this process is shown: an ignition swing at $2000 \mathrm{rev} / \mathrm{min}, 12 \mathrm{bar}$ BMEP. The fixed lambda value for the ignition swing is 1.7, a leaner mixture than was achieved in the mapping exercise. Through this process of optimisation, a best brake thermal efficiency (BTE) of $42 \%$ was achieved for the $2000 \mathrm{rev} / \mathrm{min}$, 12 bar BMEP operating condition, while NOx emissions were also reduced by more than $50 \%$ at this condition compared with the data shown in Figure 16.

\section{Vehicle Testing}

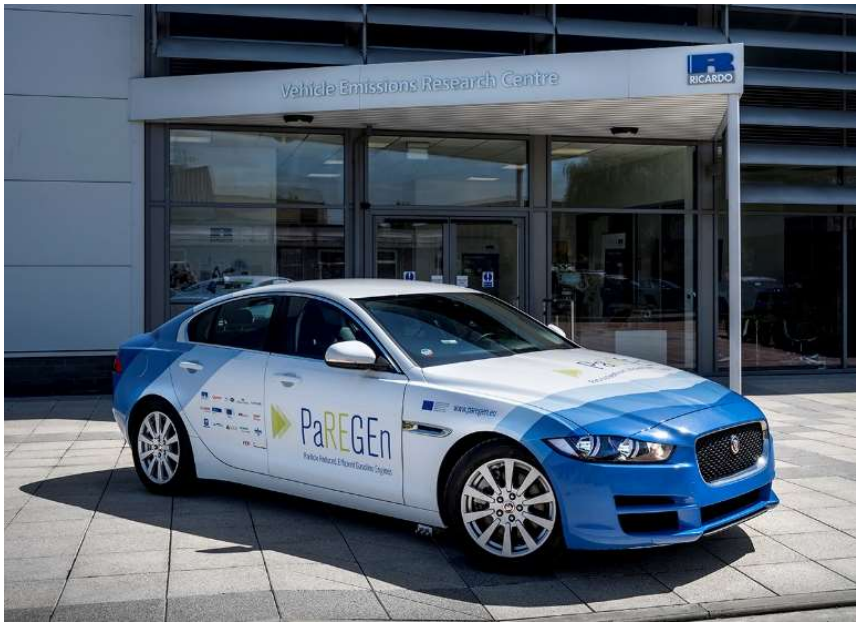

Figure 21 The PaREGEn lean demonstrator vehicle

The PaREGEn lean demonstrator vehicle is shown in Figure 21 and the engine installation is shown in Figure 22. Due to the duration of 
the project, the vehicle was fitted with the 11.0:1 compression ratio interim pistons, instead of the 12.5:1 compression ratio pistons fitted to the testbed engine.

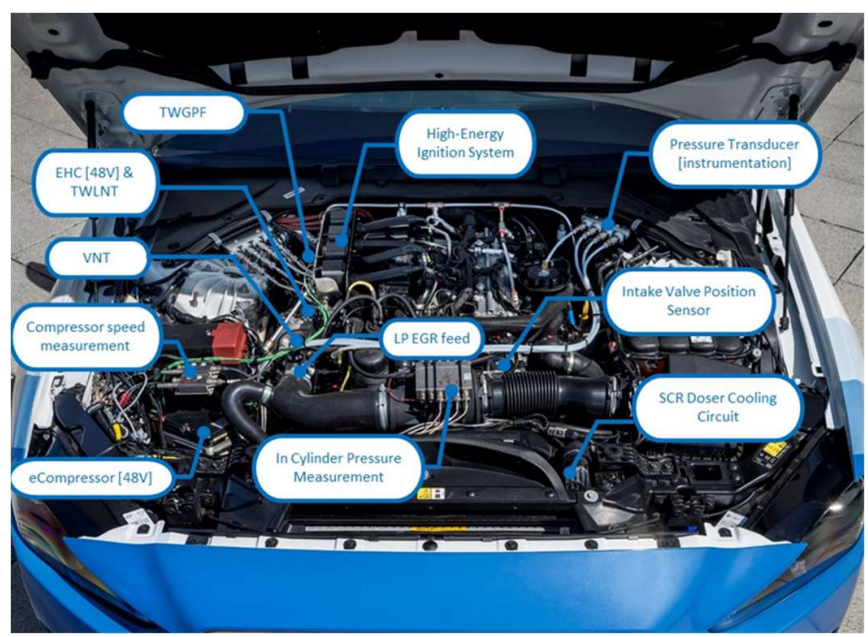

Figure 22 Under bonnet layout with the key systems identified

The vehicle has been developed and calibrated in order to meet the $\mathrm{RDE}$ emissions objectives and to demonstrate the $\mathrm{CO}_{2}$ benefits of the engine technology package. The vehicle is able to successfully transition between stoichiometric and lean operation during transient manoeuvres. Figure 23 shows an example of this. The switch event is completed rapidly, within 0.4 seconds. During the switch the incylinder charge setpoint is managed by a combination of CVVL, manifold pressure and boost pressure targets. The response of the boost actuators is shown, as the control set-points are modified, triggered by the transition mode switch. Fuelling is adjusted according to a lambda target trajectory, with the closed-loop fuelling control active throughout. Precise lambda control is required to enable effective use of the aftertreatment system and control of tailpipe emissions. This remains a challenge under transient conditions and highlights the requirement for an accurate air-path model to predict the in-cylinder charge.

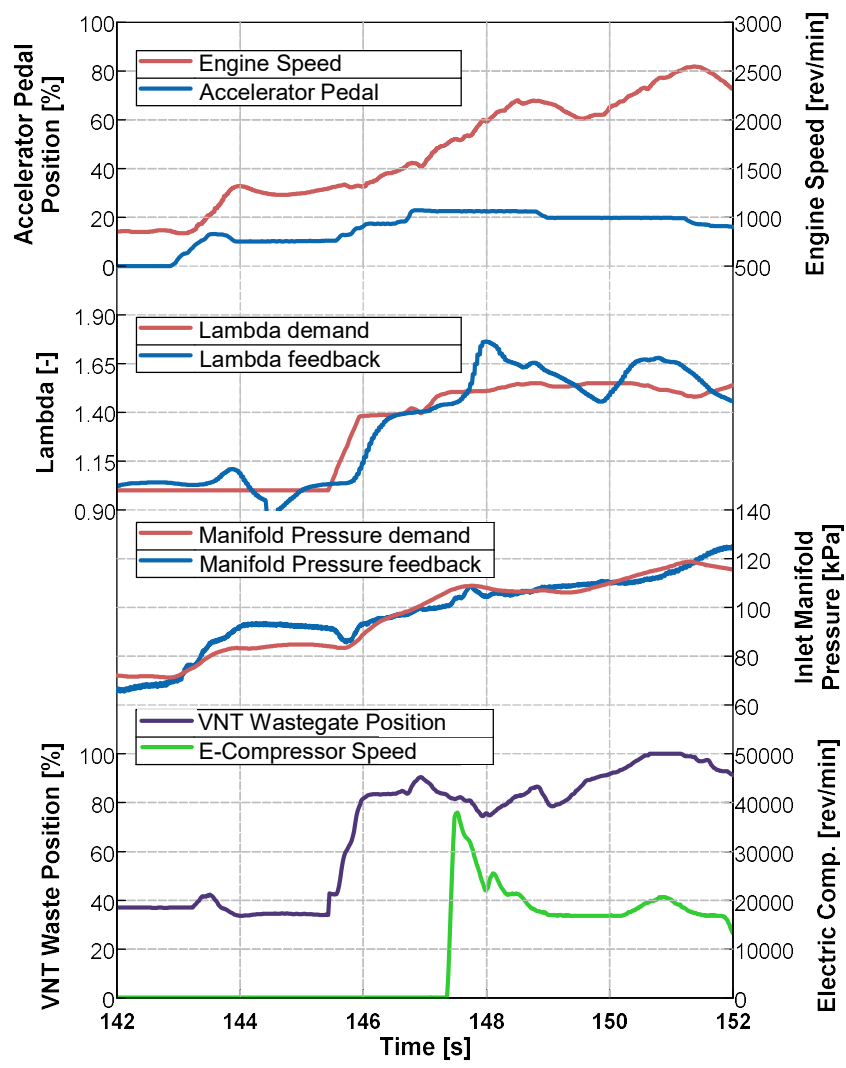

Figure 23 Example combustion mode switch in vehicle

To minimise tailpipe emissions following a cold start, it is vital that the exhaust aftertreatment is brought up to operating temperature as soon as possible. To enable this quick light-off of the three-way catalysts, a catalyst heating mode was developed, to be used in conjunction with activating the EHC. Figure 24 shows a comparison of the demonstrator vehicle with and without the EHC active. The use of the EHC led to a $\sim 40 \%$ reduction in the time the vehicle spent in catalyst heating mode and $\sim 40 \%$ reduction in the cumulative tailpipe $\mathrm{NO}_{\mathrm{x}}$. 


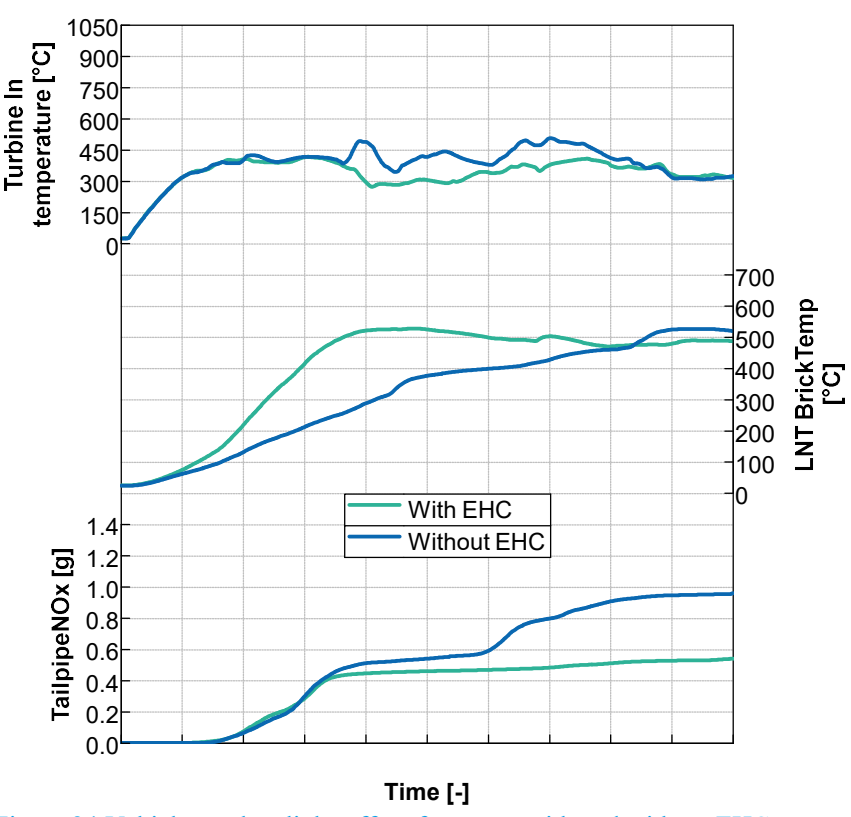

Figure 24 Vehicle catalyst light-off performance with and without EHC

In Figure 25, the final 1200 seconds of a WLTC are shown. During this period lean operation is maximised to exploit the fuel consumption benefits. A large proportion of the measured tailpipe $\mathrm{NO}_{\mathrm{x}}$ emissions are from the initial 600 seconds of the cycle, during which the engine operates only in a stoichiometric mode. The primary reason for this is the immature status of the control system. Therefore, the performance during the first 600s has been matched that of the donor XE production vehicle. With this correction made, it is estimated that the PaREGEn demonstrator can achieve the project target of $0.060 \mathrm{~g} / \mathrm{km} \mathrm{NO}$ over the cycle.

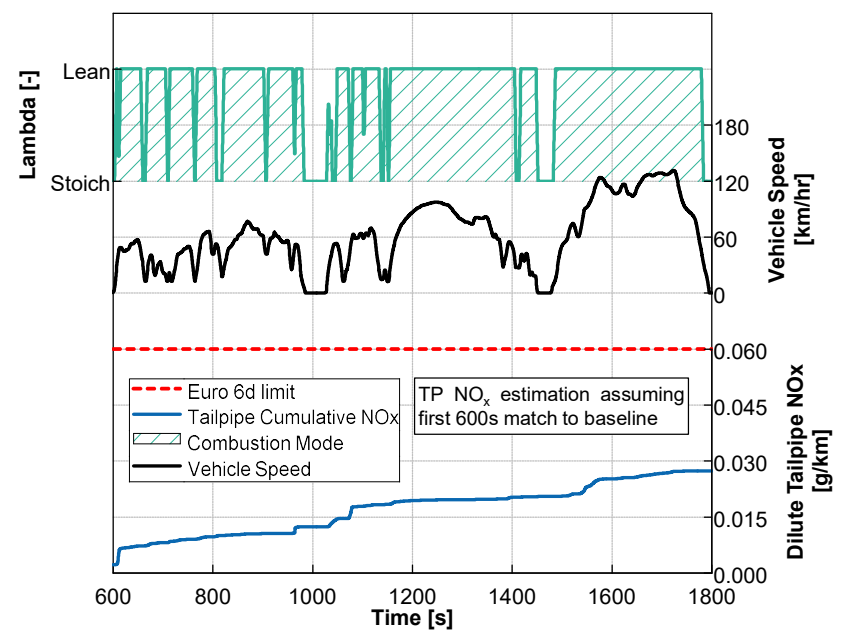

Figure 25 WLTC Lean Phase $\mathrm{NO}_{\mathrm{x}}$ emissions

In addition to the WLTC testing conducted at Ricardo, the demonstrator vehicle was also independently tested at IDIADA AUTOMOTIVE TECHNOLOGY as part of the PaREGEn project. RDE simulation testing was carried on the chassis dyno, replicating a real-life RDE cycle that meets the standard homologation conditions. Figure 26 shows the control system's ability to switch between stoichiometric and lean operation automatically. Also shown is the dilute (tailpipe) $\mathrm{NO}_{\mathrm{x}}$ emissions. The initial steep rise, $0-500 \mathrm{~s}$, is a result of the light-off of the TWC elements of the aftertreatment

Page 10 of 12 system. Whilst this impact has been reduced by the use of the EHC further benefits would be seen from improvements to the engine control system in this area. The following section, $\sim 500-3000 \mathrm{~s}$ represents the Urban phase during which the lean combustion mode is active and shows the tailpipe $\mathrm{NO}_{\mathrm{x}}$ is well controlled. The Rural phase is represented by $\sim 3000-4250 \mathrm{~s}$. During this phase some small but steep rises in the tailpipe NOx were seen. These represent higher levels of breakthrough and were due to poor AFR control under high load transient conditions. With further development, it is expected that these breakthroughs would be reduced or eliminated. The Motorway section, $\sim 4250-5650 \mathrm{~s}$ shows some similar $\mathrm{NO}_{\mathrm{x}}$ excursions. It can be seen that the system overall has good capability to control $\mathrm{NO}_{\mathrm{x}}$ under a variety of transient conditions.

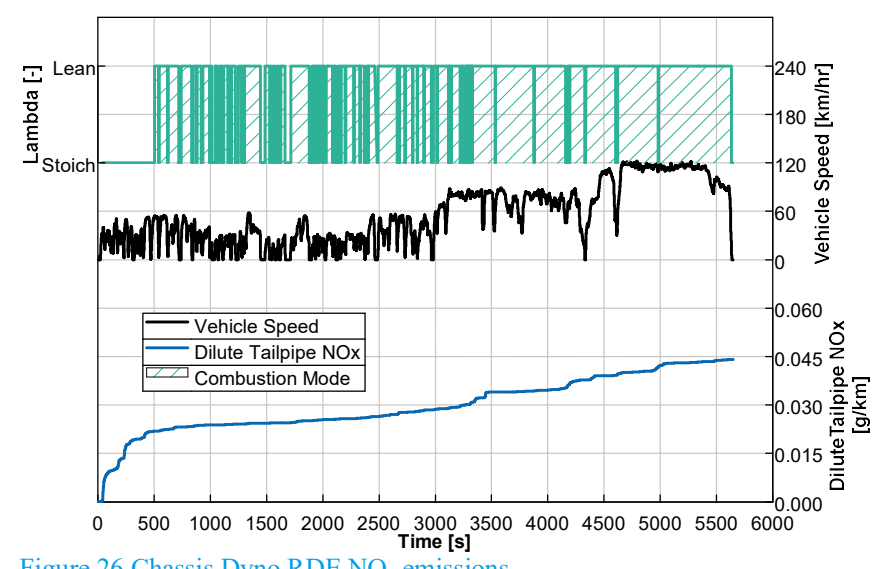

Figure 26 Chassis Dyno RDE $\mathrm{NO}_{\mathrm{x}}$ emissions

The average NOx emissions result from two chassis dyno RDE tests was $0.044 \mathrm{~g} / \mathrm{km}$ (measured by the standard CVS approach), representing a conformity factor (CF) well below 1.0 [28]. This result is inclusive of the cold-start phase and no corrections were applied to match the baseline vehicle.

The final WLTC $\mathrm{CO}_{2}$ cycle result is a combination of vehicle results and analysis using testbed data. The demonstrator vehicle by itself was not expected to meet the project target of a $15 \%$ reduction compared to baseline test results, since the timelines for the project precluded full development and optimisation of all $\mathrm{CO}_{2}$ relevant systems which would be expected on a production vehicle. Therefore, a projection has been generated, as presented in Figure 27. Each step in the projection has been calculated using a mixture of data from the demonstrator and baseline vehicles, the test engine and simulation. It includes allowances for stop-start not functioning, the vehicle being fitted with 11:1 CR pistons instead of $12.5: 1$, and the immaturity of the control system capability compared to a production level system.

The demonstrator vehicle has shown that, in spite of the challenges of lean operation (such as the requirement for regular mode switching), significant fuel savings have been made along with stringent emissions standards being met or exceeded. The key challenge for future implementation remains the complexity and cost of emissions control. 


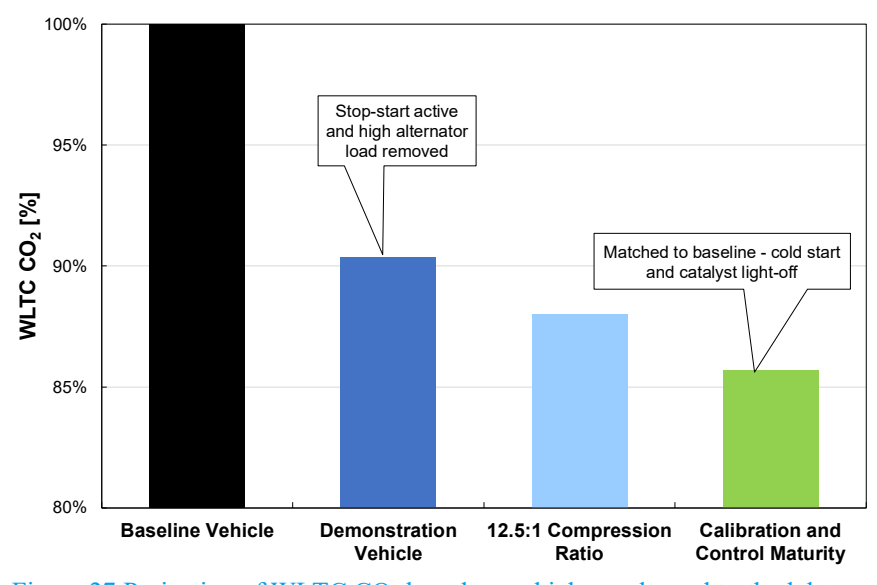

Figure 27 Projection of WLTC $\mathrm{CO}_{2}$ based on vehicle results and testbed data analysis

\section{Conclusions}

- A lean-homogeneous combustion system has been developed, incorporating direct injection, high-tumble ports and a highenergy ignition system

- This combustion system has been implemented in a 2.0 litre fourcylinder engine with a continuously-variable valve-lift system, a variable-geometry turbocharger and an electric compressor

- The engine has delivered BSFC benefits greater than $10 \%$ over a wide range of speed and load, and a peak BTE of $42 \%$

- An aftertreatment system suitable for full RDE compliance with this stoichiometric/lean switching engine has been developed, including control of lean $\mathrm{NO}_{\mathrm{x}}$ emissions and particle number emissions down to $10 \mathrm{~nm}$ diameter

- The project vehicle has demonstrated stoichiometric/lean switching under transient conditions and an independently verified $\mathrm{RDE} \mathrm{NO}_{\mathrm{x}}$ conformity factor well below 1.0

- The project has also demonstrated a route to deliver close to the $15 \%$ reduction in vehicle $\mathrm{CO}_{2}$ emissions sought by the call within the Horizon 20202016 work programme, through a combination of physical prototype testing and analytical approaches

\section{References}

1. European Commission.: Horizon 2020, Work Programme 2016 -2017, 11. Smart, green and integrated transport. June 2015.

2. Edwards, S. Gidney, J. Freisinger, N., Turner, N., Perez, A. and van der Zweep, C.: "Particle Reduced, Efficient Gasoline Engines: A final report on the PaREGEn project". Proceedings of 8th Transport Research Arena TRA 2020, April 27-30, 2020, Helsinki, Finland

3. PaREGEn project website www.paregen.eu.

4. Ricardo, H. R.: "Recent Research Work on the InternalCombustion Engine", SAE Annual Meeting, 10-13 January 1922.

5. Lake, T. H., Sapsford, S. M., Stokes, J. and Jackson, N. S.: "Simulation and Development Experience of a Stratified Charge Gasoline Direct Injection Engine". SAE Technical Paper 962014, San Antonio, 1996.

6. Iwamoto, Y., Noma, K., Nakayama, O., Yamauchi, T. and Ando, O.: "Development of Gasoline Direct Injection Engine". SAE Technical Paper 970541, Detroit, February 1997.

7. Harada, J., Tomita, T., Mizuno H., Mashiki, Z., Ito, Y.: "Development of Direct Injection Gasoline Engine". SAE Technical Paper 970540.
8. Krebs, R., Spiegel, L., Stiebels, B.: "Ottomotoren mit Direkteinspritaung von Volkswagen". 8th Aachen Colloquium on Vehicle and Engine Technology, 5-6 October 1999.

9. Lückert, P.; Waltner, A.; Rau, E., Vent, G. and Schaupp, U. "The New V6 Gasoline Engine with Direct Injection by Mercedes-Benz". MTZ $11 \mid$ 2006, Volume 67.

10. Schwarz, C.; Schunemann, E.; Durst, B.; Fischer, J. and Witt, A "Potentials of the Spray-Guided BMW DI Combustion System". SAE Technical Paper 2006-01-1265.

11. Waltner, A.; Lückert, P.; Breitbach, H.; Doll, G., Herwig, H., Kemmler, R. and Weckenmann, H. "The New V6 Petrol Engine with Direct Injection from Mercedes-Benz". 31st International Vienna Engine Symposium 2010.

12. Schmidt, L.; Seabrook, J.; Stokes, J.; King, J.; Faizan, M.; Zuhdi, A.; Begg, S. and Heikal, M.: "Multiple Injection Strategies for Improved Combustion Stability under Stratified Part Load Conditions in a Spray Guided Gasoline Direct Injection (SGDI) Engine". SAE Technical Paper 2011-01-1228.

13. Stokes, J.; Lake, T. H. and Osborne, R. J.: "A Gasoline Engine Concept for Improved Fuel Economy - The Lean Boost System", SAE Technical Paper 2000-01-2902, Baltimore, October 2000.

14. Lake, T. H., Stokes, J., Murphy, R. D. and Osborne, R. J. "Turbocharging Concepts for Downsized DI Gasoline Engines", 12. Aachener Kolloquium Fahrzeug- und Motorentechnik, 2003.

15. Vent, G.; Enderle, C.; Merdes, N.; Kreitmann, F. and Weller, R.: "The New 2.01 Turbo Engine from the Mercedes-Benz 4Cylinder Engine Family". 21 st Aachen Colloquium Automobile and Engine Technology 2012.

16. Hiroshi Hanabusa, Takashi Kondo, Kohtaro Hashimoto, Hiroshi Sono, Masahiro Furutani: "Study on Homogeneous Lean Charge Spark Ignition Combustion”. SAE Technical Paper 2013-012562.

17. Scarcelli, R., Matthias, N., and Wallner, T., "Numerical Investigation of Combustion in a Lean Burn Gasoline Engine," SAE Technical Paper 2013-24-0029, 2013, doi:10.4271/2013-24-0029.

18. Doornbos, G., Hemdal, S., and Dahl, D.: "Reduction of Fuel Consumption and Engine-out NOx Emissions in a Lean Homogeneous GDI Combustion System, Utilizing Valve Timing and an Advanced Ignition System". SAE Technical Paper 2015-01-0776, 2015, doi:10.4271/2015-01-0776.

19. Nakata, K., Nogawa, S., Takahashi, D., Yoshihara, Y., Kumagai, A. and Suzuki, T.: "Engine Technologies for Achieving $45 \%$ Thermal Efficiency of S.I. Engine". SAE Int. J. Engines 9(1):2016, doi:10.4271/2015-01-1896.

20. Takahashi, D., Nakata, K., Yoshihara, Y., and Omura, T., "Combustion Development to Realize High Thermal Efficiency Engines," SAE Int. J. Engines 9(3):2016, doi:10.4271/2016-010693.

21. Philipp Adomeit, Johannes Scharf, Matthias Thewes, Bastian Morcinkowski, Patrick Hoppe, Stefania Esposito, Marius Böhmer: "Extreme Lean Gasoline Technology - Best Efficiency and Lowest Emission Powertrains". ATZ Live $4^{\text {th }}$ International Engine Congress, 2017.

22. Clasen, K. and Koopmans, L., "Investigation of Homogeneous Lean SI Combustion in High Load Operating Conditions," SAE Technical Paper 2020-01-0959, 2020, doi:10.4271/2020-010959.

23. Osborne, R., Lane, A., Turner, N., McWilliam, L. et al., "A New-Generation Lean Gasoline Engine for Reduced $\mathrm{CO}_{2}$ in an Electrified World," presented at in the 40th International Vienna Motor Symposium, Vienna, May 2019.

24. Talue, D., Whitwood, P., Page, G., McAllister, M., Borean, F. and Penfold, R.: "Introducing the Ingenium SI Engine: Jaguar

Page 11 of 12 
Land Rover's New Four-Cylinder Gasoline Engine". 38. Internationales Wiener Motorensymposium, May 2017.

25. Brandt, M., Hettinger, A., Schneider, A., Senftleben, H. and Skowronek, T.: "Extension of Operating Window for Modern Combustion Systems by High Performance Ignition". Published in M. Günther and M. Sens (eds.), Ignition Systems for Gasoline Engines, Springer, Switzerland, 2016. doi:10.1007/978-3-31945504-4 2.

26. Pohorelsky, L., A. Vondrak, N. Turner, N. Luard, B. Cooper, A. Lane, R. Osborne, "The Coupling of Advanced Gasoline Combustion and a Fast-Transient Boost System to Produce a Low $\mathrm{CO}_{2}$ vehicle Concept," Dresden, October 2018.

27. Seabrook, J., Salamon, T., Edwards, S. P., Noell, I.: “A Comparison of Neural Networks, Stochastic Process Methods and Radial Basis Functions for the Optimization of Engine Control Parameters". Haus der Technik - 2nd Conference on Design of Experiments in Engine Development, Berlin, 2003.

28. Pérez, A., Paz, S.: PaREGEn D5.3 "Independent testing of the demonstrator vehicles", PaREGEn.EU, 11.01.2020, https://paregen.eu/project/paregen-results/

\section{Acknowledgements}

The authors would like to thank their Directors and the project partners for permission to publish this paper. The contributions of Tom Laight, Yuanping Li, Andrew Murphy, Gareth Jones and Sam Davies of Ricardo, and Giorgio Mancini, Shihui Liu, Celso Acurcio, Bogdan Bokor and Venkataraghavan Nagarajan of Jaguar Land Rover to the work reported is also gratefully acknowledged. This project has received funding from the European Union's Horizon 2020 research and innovation programme under grant agreement No. 723954. The information and views set out in this publication do not necessarily reflect the official opinion of the European Commission. Neither the European Union institutions and bodies, nor any person acting on their behalf, may be held responsible for the use which may be made of the information contained therein.

\section{Abbreviations}

$\begin{array}{ll}\text { AFR } & \text { Air-Fuel Ratio } \\ \text { BSFC } & \text { Brake Specific Fuel Consumption } \\ \text { BTE } & \text { Brake Thermal Efficiency } \\ \text { CF } & \text { Conformity Factor } \\ \text { CR } & \text { Compression Ratio } \\ \text { CVS } & \text { Constant Volume Sampling } \\ \text { CVVL } & \text { Continuously-Variable Valve-Lift } \\ \text { DCU } & \text { Dosing Control Unit } \\ \text { DOHC } & \text { Double Overhead Cam } \\ \text { ECU } & \text { Engine Control Unit } \\ \text { EGR } & \text { Exhaust Gas Recirculation } \\ \text { EHC } & \text { Electrically-Heated Catalyst }\end{array}$

Page 12 of 12
FIE

GPF

IMEP

MFB

PaREGEn

RDE

SCR

SPCS

SPM

TWC

TWLNT

TWGPF

VCT

VNT

WLTC
Fuel Injection Equipment

Gasoline Particle Filter

Indicated Mean Effective Pressure

Mass Fraction Burned

Particle Reduced, Efficient Gasoline Engines

Real Driving Emissions

Selective Catalytic Reduction

Solid Particle Counting System

Stochastic Process Model

Three-Way Catalyst

Three-Way Lean $\mathrm{NO}_{x}$ Trap

Three-Way Gasoline Particulate Filter

Variable Cam Timing

Variable Nozzle Turbocharger

World Light-duty harmonised Test Cycle 